\title{
Association of Seizure, Facial Dysmorphism, Congenital Umbilical Hernia and Undescended Testes
}

\author{
Thapa LJ, Pokharel BR, Paudel R, Rana PVS
}

Department of Neurology

College of Medical Sciences

Bharatpur, Chitwan, Nepal.

Corresponding Author

PVS Rana

Department of Medicine and Neurology

College of Medical Sciences

Bharatpur, Chitwan, Nepal.

Email: rananirmalpvs@gmail.com

Citation

ThapaLJ, Pokharel BR, Paudel R, Rana PVS. Association of Seizure, Facial Dysmorphism, Congenital Umbilical Hernia and Undescended Testes: A Case Report. Kathmandu Univ Med J 2012;37(1):91-3.

\begin{abstract}
With the advances in neurogenetics association of epilepsy and intellectual disability with chromosomal abnormalities are being increasingly recognized. While onset of seizures with mental retardation at an early age indicate chromosomal abnormality, combination of characteristics facial dysmorphism and congenital abnormalities gives a clue of a particular syndrome. In addition MRI findings may help in confirming the diagnosis. A nine years old boy is presented where early onset seizure, mental retardation, delayed development of speech, presence of facial dysmorphism,, umbilical hernia and undescended testes suggested possibility of chromosomal $6 q$ deletion disorder. Important deletion disorders are discussed and importance of clinical examination is stressed.
\end{abstract}

\section{KEY WORDS}

Chromosome deletion, Cryptorchidism, Facial dysmorphism, Seizures, Umbilical hernia

\section{INTRODUCTION}

Abnormalities of chromosome structure consist primarily of deletion syndromes (i.e. caused by a chromosome break and subsequent loss of genetic material), duplication syndromes (i.e. with an additional chromosome material) and translocations (interchange of genetic material between non homologous chromosomes). Duplications or deletions of large amounts of chromosome, with few exceptions, are not compatible with survival. These chromosomal disorders are rare disorders . Approximately $06 \%$ of patients having seizures and intellectual abnormalities show chromosomal abnormalities but it rises to $50 \%$ when seizure is associated with facial dysmorphism and congenital systemic abnormalities. ${ }^{1}$ With the development of finer cytogenetic methods, smaller deletions ("microdeletions") associated with milder phenotypes are being recognized. Singh et al. analyzed the published literature and noted 39 important imbalances distributed mainly on 11 autosomes and the $X$ chromosome. ${ }^{2}$ The majority of reported "classic" deletion syndromes have a phenotype of early onset seizure, intellectual disability and congenital malformations. . $^{2-4}$ Inspite of considerable overlap in phenotypic presentation, chromosomal abnormalities can be recognized by careful clinical examination as illustrated by the case reported.

\section{CASE REPORT}

A nine years old boy, born of a non consanguineous marriage, presented with recurrent generalized tonic seizures from the age of two years. Initially seizures occurred during febrile illness only. When seen he was on carbamazepine therapy and was getting two to three seizures per month. The prenatal, natal and post natal history was normal. At birth, he had difficulty in breathing requiring medical attention. He started speaking with hoarse voice at three years. His other milestones were normal. He was poor in his studies. When seen the child was hyperactive. The neurological examination was normal. Physical examination showed broad nose with depressed bridge, increased inter-canthal distance (Fig 1a), low set ears (Fig-1b), thin upper lip, umbilical hernia (Fig-1c) and undescended testes (Fig-1d). Investigations i.e. hemogram, metabolic parameters, X-Ray chest and MRI were normal. 


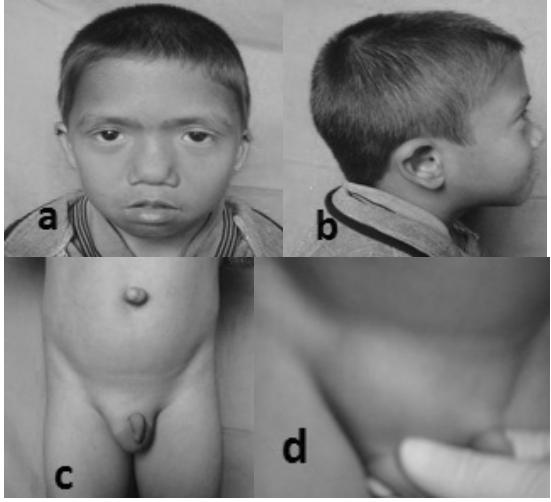

Figure 1. (a) Hypertelorism, broad nose, (b) low set ears, (c) umbilical hernia, (d) undescended testis

EEG was confirmatory for epilepsy and revealed slowing to 3-4 HZ intermixed with high voltage sharp waves from fronto-temporal region (Fig 2)

\section{DISCUSSION}

The patient under discussion had early onset generalized tonic-clonic seizures, widely spaced eyes, low set ears, thin upper lip, delayed speech development, poor scholastic performance, umbilical hernia and undescended testes, suggesting a chromosomal deletion syndrome.

Besides early seizures and mental retardation in the affected child, chromosomal deletion disorders have characteristics combination of facial dysmorphism and congenital systemic abnormalities. Umbilical hernia and undescended testes in reported in most of these disorders. The diagnostic features of common deletion syndromes, absent in present case, were (a) microcephaly, high-pitched shrill cry, abnormal posturing, autonomic features and corpus callosal agenesis of chromosomal 1q42-43 deletion syndrome; (b) Short stature, brachymetaphalangy of 3-5 digits, autism, joints hypermobility/dislocations and scoliosis of chromosomal 2q37 deletion syndrome; (c) microcephaly and typical "Greek helmet" appearance of 4-p16.3 deletion (WolfHirschhorn) Syndrome; (d) microcephaly, and multiple exostosistosis of chromosome 8q 24.12 deletion (LangerGiedion) syndrome; (d) brachy- microcephaly, mid facial hypoplasia, deep set eyes, macrostomia and prominent mandible and speech of few words of 15q11-13 deletion (Agelman) syndrome; (e) congenital heart disease, palatal abnormalities, immune deficiency states, hypocalcemia, hearing loss, laryngo-tracheo-esophageal anomalies, presence of autoimmune disorders and growth hormone deficiency of chromosome 22q11.2 deletion (Di George) Syndrome respectively. ${ }^{2-10}$

A normal MRI in the present case excluded 1q 42-43 syndrome (discussed above) and, 17-p13.3 deletion syndrome of Miler-Diecker which is associated with lissencephaly, profound intellectual disability, microcephaly, characteristics facies and atonic diplegia. ${ }^{2-4,11}$ It also excluded CHARGE syndrome due to mutation of $\mathrm{CHD} 7$

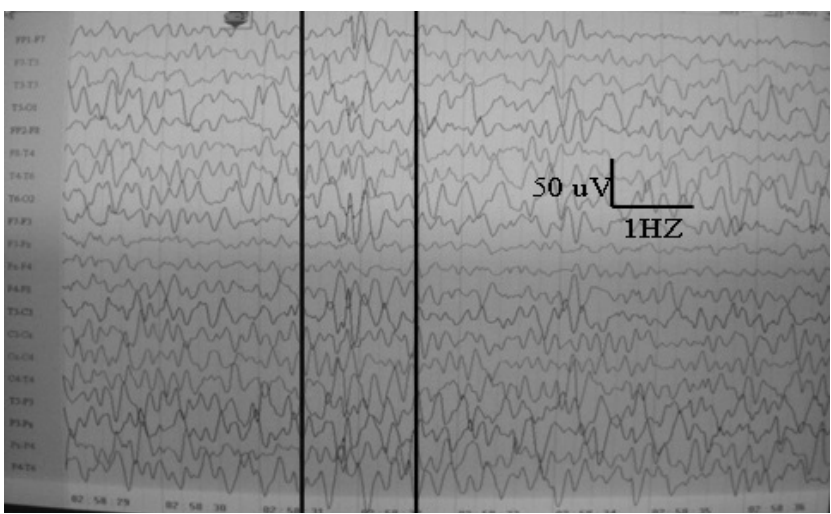

Figure 2 : EEG showing Excess of slowing fronto-temporal region with sharp dicharges

gene located on the long arm of chromosome 8 having $1^{\text {st }}, 9^{\text {th }}, 10^{\text {th }}$ and $7^{\text {th }}$ cranial nerve involvement, ocular and ear abnormalities and congenital systemic abnormalities and Acrocallosal syndrome of Schinzel type, an autosomal recessive disorder characterized by craniofacial anomalies, hallux duplication and polydacyly. ${ }^{12,13}$ Both of which are associated with agenesis of corpus callosum and are reported to have combination of seizures, mental retardation, umbilical hernia and undescended testes.

Our patient shares several major features of $6 q$ interstitial deletions syndrome with proximal breakpoints $6 q 13 q 15$ and $6 q 14$ or $q 15 q 16$. Chromosome -6 Interstitial deletions of the long arm of chromosome are few. Their clinical phenotype varies. The affected children needs supports in breathing at early stage and suffer from early onset generalized tonic clonic seizures, with onset of seizure between 1-4 years. The children have typical dysmorphic facies with short palpebral fissures and thin upper lip and inguinal hernias. In other reports, umbilical hernias and undescended testes have been reported. ${ }^{14}$ We believe it is likely diagnosis in this case and need confirmation by further cytogenetic investigations. Further chromosomal $6 \mathrm{q}$ terminal deletion has different presentation consisting of microcephaly, hydrocephalus, colpocephaly (large occipital horn) and congenital heart disease. Chromosomal $6-p$ terminal deletion (6p24- and 6p25) also exhibit a different recognizable pattern of malformations including hypertelorism, down slanting palpebral fissures, flat nasal bridge, Dandy-Walker malformation/variant, congenital heart defects, anterior eye-chamber abnormalities, hearing loss, and developmental delay. ${ }^{15}$

Chromosomal deletion syndromes though rare, should be suspected and needs confirmation by cytogenic studies. Understanding of these disorders is important as correct diagnosis helps in predicting the natural history of epilepsy and to give correct counseling to the parents. 


\section{REFERENCES}

1. Leshima A, Takeshita K. Chromosome abnormalities and epileptic seizures. Jpn J Hum Genet 1988;33:49-60.

2. Singh R, Gardner RJ, Crossland KM, Scheffer IE, Berkovic SF. Chromosomal abnormalities and epilepsy: a review for clinicians and gene hunters. Epilepsia 2002; 43:127-40.

3. Trieman LJ, Triemen DM. Genetics and chromosomal disorders in epilepsy. In: Whelles JW, Willmore LJ, Brumack RA (eds). Advanced therapy in Epilepsy. Shelton, Connecticut: People Medical Publishing House; 2009. p. 67-76.

4. Agatino BA, Guerrini R. Chromosomal disorders associated with epilepsy. Epileptic Disord 2005;7(3):181-92.

5. Howard PJ, Porteus M. Deletion of chromosome 1p: a short review. Clin Genet 1990;37:127-31.

6. Sanchez JM, Pantano AM. A case of deletion 2 q35 $\rightarrow$ qter and a peculiar phenotype. J Med Genet 1984;21:147-9.

7. Battaglia A, Carey JC. Update on the clinical features and natural history of Wolf-Hirschhorn syndrome (WHS): experience with 48 cases. Am J Hum Genet 2000; 6: 127.

8. Stoltzfus E, Ladda RL, Lloyd-Still J. Langer-Giedion syndrome: type II tricho-rhino- phalangeal dysplasia. J Pediatr 1977;91:277-80.
9. Williams CA. Neurological aspects of the Angelman syndrome. Brain Dev 2005;27:88-94.

10. Wilson DI, Burn J, Scambler P, Goodship JJ. DiGeorge syndrome: part of CATCH 22. Med Genet 1993;30:852-6.

11. Dobyns WB, Curry CJ, Hoyme HE, Turlington L, Ledbetter DH. Clinical and molecular diagnosis of Miller-Dieker syndrome. Am J Hum Genet 1991;48(3):584-94.

12. Blake $A E$, Devenport SLH, Hall BD, Hefne MA, Pagon RA Williams $\mathrm{MS}$, et al. Charge association: An update and review for primary pediatrician. Clin Paediatr 1998;37:159-74.

13. Schinzel A. Four patients including two sisters with the acrocallosal syndrome (agenesis of the corpus callosum in combination with preaxial hexadactyly). Hum Genet 1982;62(4):382-4.

14. White BJ, Schwartz AT, Levin SW, Coil EJ, Anguiano A, Wang S, et al. Proximal $6 q$ deletion phenotype: findings in de novo interstitial deletion 6g14.1g15. Genetics in Medicine 2000;2:96.

15. Lin RJ, Cherry AM, Chen KC, Lyons M, Hoyme HE, Hudgins L. Terminal deletion of $6 p$ results in a recognizable phenotype. Am J Genetics 2005;136:162-8. 